https://helda.helsinki.fi

\title{
Empathizing-Systemizing Theory
}

\section{Lindeman, Marjaana}

Springer International Publishing 2017

Lindeman , M 2017 , Empathizing-Systemizing Theory . in V Zeigler-Hill \& T K Shackelford (eds) , Encyclopedia of Personality and Individual Differences . Springer International Publishing , [Cham] , pp. 1-3 . https://doi.org/10.1007/978-3-319-28099-8_1129-1

http://hdl.handle.net/10138/309981

https://doi.org/10.1007/978-3-319-28099-8_1129-1

unspecified

acceptedVersion

Downloaded from Helda, University of Helsinki institutional repository.

This is an electronic reprint of the original article.

This reprint may differ from the original in pagination and typographic detail.

Please cite the original version. 


\section{Empathizing-Systemizing Theory}

\section{Related terms}

Theory of mind, mentalizing, intuitive psychology, intuitive physics, mechanistic cognition

\section{Definition}

Empathizing-Systemizing (E-S) theory concerns two fundamental cognitive processes known as empathizing and systemizing. It was developed by Simon Baron-Cohen in the early 2000s, and endeavors to explain autism and Asperger syndrome as well as sex differences in the general population (Baron-Cohen, 2002, 2009; Baron-Cohen, 2010; Baron-Cohen, Knickmeyer, \& Belmonte, 2005).

\section{Introduction}

As with many other empathy researchers, Baron-Cohen describes empathizing as consisting of two components, cognitive and affective empathy. Cognitive empathy means a drive to identify another person's emotions and thoughts, as well as an ability to put oneself into someone else's shoes and to imagine their thoughts and feelings. Affective empathy in the E-S theory is a response element, that is to say, having an appropriate emotional reaction to another person's thoughts and feelings.

Systemizing is defined as a drive to analyze or construct systems. A system is something that follows rules. When we systemize we are attempting to identify the rules that govern the system. The concept of systemizing is derived from intuitive physics. Whereas intuitive physics focuses mainly on physical causal systems, systemizing also involves understanding the rules governing non-causal systems such as libraries or timetables (Wakabayashi et al., 2007). E-S theory describes several types of systems, including mechanical (e.g., machines), motoric (e.g., sports techniques), abstract (e.g., mathematics), organizable (e.g., plant taxonomies), numerical (e.g., calendars), natural (e.g., the weather patterns), sensory (e.g., wanting the same food each day), and social systems (e.g., law).

Empathizing and systemizing are suggested to be independent dimensions that are present to varying degrees in the general population. An individual can thus be either good or poor at both, or at one or the other. E-S theory has two basic premises, as follows. First, more females than males have a femaletype cognition (empathizing is more developed than systemizing) and more males than females have a 
male-type cognition (systemizing is more developed than empathizing). These two types of cognition are also referred to as female brain and male brain type, and they are proposed to be determined both by biology and socialization. Second, individuals with autism or Asperger syndrome are proposed to show a delayed ability to empathize, and an average or even above-average ability to systemize. Baron-Cohen (2002) refers to this extension of E-S theory as the extreme male brain theory of autism. Genetic and hormonal factors may predict sex differences and autistic traits, but their exact nature is not known.

\section{Assessment of empathizing and systemizing}

To assess empathizing, systemizing, and autistic traits, Baron-Cohen and colleagues have developed the Empathy Quotient (EQ), the Systemizing Quotient (SQ), and the Autism-Spectrum Quotient (AQ). The $E Q$ is a questionnaire that includes 40 empathy items and 20 filler items (Baron-Cohen \& Wheelwright, 2004). Systemizing can be assessed with the Systemizing Quotient-Revised (Wheelwright et al., 2006), a 75-item self-report scale (for the original SQ, see Baron-Cohen, Richler, Bisarya, Gurunathan, \& Wheelwright, 2003). The AQ questionnaire has 50 items and was developed to assess autistic traits among adults with normal intelligence (Baron-Cohen, Wheelwright, Skinner, Martin, \& Clubley, 2001). The AQ items partly overlap the EQ and SQ items.

In addition, the website of the Cambridge University Autism Research Centre, led by Baron-Cohen, includes several other tests in different languages for children, adolescents and adults. The tests can be downloaded, and they focus on different manifestations of empathizing, systemizing, and autistic traits.

Researchers are working to further develop methods by which empathizing, systemizing and related constructs could be studied in greater detail. Apart from the EQ and other empathy self-report measures, methods assessing actual empathizing abilities among healthy adults in particular are limited.

\section{Evidence}

In the early days of E-S theory, Baron-Cohen reviewed evidence for the theory from previous findings on sex differences and on individuals with autism spectrum disorder (Baron-Cohen, 2002; Baron-Cohen et al., 2005). This evidence shows, for example, that 1-day-old boys look longer at a mechanical mobile than at a person's face whereas 1-day-old girls show the opposite preference. In addition, females are better at 
emotion recognition, and in terms of social sensitivity, they are more interested in people, and value developing altruistic relationships. Girls begin to speak earlier than boys, they talk more about feelings, and are more likely to play with dolls as children. Males, in contrast, are often better at mental rotation, spatial navigation, map reading, and problems concerning mathematics, physics and engineering; they have better constructional abilities, they more often choose occupations linked to systemizing (e.g., in fields involving engineering and mathematics), and they are more likely to play with mechanical toys as children.

In addition, individuals with autism spectrum disorder are more often male than female, and they show deficits in domains relating to empathizing whereas their abilities relating to systemizing are normal, or even superior to males that have no autism spectrum disorder. Their superior abilities are manifested as extra-close attention to detail and a passion for collecting and organizing things, and sometimes also as exceptional achievements, for example in mathematics, science or chess. Moreover, they score higher than average on tests relating to intuitive physics and systemizing, and their fathers and grandfathers are overrepresented in occupations that require good systemizing.

The empirical research designed to test E-S theory directly has been extensive. Most of the studies have focused on autistic traits, and to a lesser extent, on gender differences. The role of empathizing and systemizing in such areas as brain function, decision making, learning, thinking, personality, religiosity, social intelligence, and occupational choices has also been researched. In addition to other researchers internationally, Baron-Cohen and colleagues have conducted hundreds of studies to empirically test E-S theory. The articles are available at the website of the Cambridge University Autism Research Centre. As a whole, the results broadly support the theory's main propositions.

\section{Critique of the theory}

Although most researchers accept Baron-Cohen's major premises and propositions, the theory has also received criticism. Some critics argue that many of the studies have used only self-report measures, such as $\mathrm{EQ}, \mathrm{SQ}$ and $\mathrm{AQ}$, and have focused mainly on high-functioning autism. Whether self-perceptions are accurate and whether the results apply to autistic individuals who have intellectual disabilities is said to be uncertain. Critics also claim that the arguments about sex differences are exaggerated, and that males and 
females have equal abilities in terms of language learning, spatial reasoning, and mathematical and scientific thinking. Moreover, some researchers regard the concept of systemizing as ambiguous. For example, Badcock (2009) suggests that mechanistic cognition, rather than systemizing, would be a better term for concrete, repetitive and literal autistic thinking, which tends to miss the deeper meaning of the systems.

\section{Conclusion}

Despite some criticism, E-S theory is a valuable addition to the fields of autism spectrum disorders, gender differences, as well as personality and cognition in general. The definitions of the terms 'empathizing' and 'systemizing' are detailed, the theory is clear in its proposals, and it has high explanatory and predictive power. Probably for these reasons, E-S theory has triggered an exceptionally large amount of theoretical and empirical work during its short history.

\section{References}

Badcock, C. (2009). The imprinted brain. Dexter, MI: Thomson-Shore.

Baron-Cohen, S. (2002). The extreme male brain theory of autism. Trends in Cognitive Sciences, 6, 248-254. doi: 10.1016/S1364-6613(02)01904-6

Baron-Cohen, S. (2009). Autism: The Empathizing-Systemizing (ES) Theory. Annals of the New York Academy of Sciences, 1156, 68-80.

Baron-Cohen, S. (2010). Empathizing, systemizing, and the extreme male brain theory of autism. In I. Savic (Ed.), Sex differences in the human brain, their underpinnings and implications. (pp. 167-175). New York: Academic Press.

Baron-Cohen, S., Knickmeyer, R. C., \& Belmonte, M. K. (2005). Sex differences in the brain: Implications for explaining autism. Science, 310, 819-823. doi: 10.1126/science.1115455

Baron-Cohen, S., Richler, J., Bisarya, D., Gurunathan, N., \& Wheelwright, S. (2003). The systemizing quotient: An investigation of adults with Asperger syndrome or high-functioning autism, and 
normal sex differences. Philosophical Transactions of the Royal Society B: Biological Sciences, 358, 361-374. doi: 10.1098/rstb.2002.1206

Baron-Cohen, S., \& Wheelwright, S. (2004). The Empathy Quotient: An investigation of adults with Asperger syndrome or high functioning autism, and normal sex differences. Journal of Autism and Developmental Disorders, 34, 163-175. doi: 10.1023/B:JADD.0000022607.19833.00

Baron-Cohen, S., Wheelwright, S., Skinner, R., Martin, J., \& Clubley, E. (2001). The autism-spectrum quotient (AQ): Evidence from Asperger syndrome/high-functioning autism, males and females, scientists and mathematicians. Journal of Autism and Developmental Disorders, 31, 5-17. doi: 10.1023/A:1005653411471

Wakabayashi, A., Baron-Cohen, S., Uchiyama, T., Yoshida, Y., Kuroda, M., \& Wheelwright, S. (2007). Empathizing and systemizing in adults with and without autism spectrum conditions: cross-cultural stability. Journal of Autism and Developmental Disorders, 37, 1823-1832. doi: 10.1007/s10803-006$0316-6$

Wheelwright, S., Baron-Cohen, S., Goldenfeld, N., Delaney, J., Fine, D., Smith, R., . . Wakabayashi, A. (2006). Predicting Autism Spectrum Quotient (AQ) from the Systemizing Quotient-Revised (SQ-R) and Empathy Quotient (EQ). Brain Research, 1079, 47-56. doi: 10.1016/j.brainres.2006.01.012 